\title{
Morfología y vascularización de los nervios cubital y mediano en la región braquial del perro
}

\author{
Llano, E.G.; Flores Quintana, C.I.; Báez, A.D.; Cabrera, W.R.; Benítez, J.S.
}

Cátedras de Anatomía II e Histología y Embriología, Facultad de Ciencias Veterinarias, Universidad Nacional del Nordeste, Sargento Cabral 2139, Corrientes (3400), Argentina. E-mail: anato2@vet.unne.edu.ar.

\begin{abstract}
Resumen
Llano, E.G.; Flores Quintana, C.I.; Báez, A.D.; Cabrera, W.R.; Benítez, J.S.: Morfología y vascularización de los nervios cubital y mediano en la región braquial del perro. Rev. vet. 22: 2, 109-113, 2011. El objetivo del trabajo fue identificar el origen y distribución segmentaria de los vasos sanguíneos que constituyen el sistema extrínseco de vascularización y determinar algunos parámetros morfométricos de los nervios cubital y mediano en la región braquial del perro. Se trabajó con 6 miembros anteriores de caninos que fueron inyectados con látex coloreado, tras lo cual se disecaron los nervios y su correspondiente irrigación. A partir de cortes transversales del tronco nervioso se realizaron preparados histológicos teñidos con hematoxilina y eosina, determinándose por microscopía óptica el número y la distribución de los fascículos, agrupándose las fibras en dos categorías acorde a su diámetro (hasta 6 y más de 6 um). Se midieron el área de los fascículos y la distancia entre epineuro y perineuro. En el 57\% de los casos los segmentos proximal y distal de los nervios cubital y mediano estaban irrigados por pequeñas ramas que se desprendían de la arteria braquial; en el segmento proximal también se observaron pequeños vasos que se originaban de la arteria torácica externa y braquial profunda. En el segmento distal se observaron pequeñas ramas originadas de la arteria bicipital y braquial profunda. En cuanto a la conformación y morfometría, en el segmento proximal se observó un promedio de 3 fascículos, un área media de $0,96 \mathrm{~mm}^{2}$ y una distancia de $0,7 \mathrm{~mm}$ entre epineuro y perineuro. La medición del diámetro de las fibras en este segmento determinó un $40 \%$ en la categoría 1 y $60 \%$ en la categoría 2 . En el segmento distal se observó un promedio de 4 fascículos, un área media de $0,65 \mathrm{~mm}^{2}$ y una distancia de $0,73 \mathrm{~mm}$ entre epineuro y perineuro. La medición del diámetro de las fibras en este segmento determinó un $41 \%$ en la categoría 1 y $59 \%$ en la categoría 2 .
\end{abstract}

Palabras clave: perro, nervios cubital y mediano, fascículos, irrigación.

\begin{abstract}
Llano, E.G.; Flores Quintana, C.I.; Báez, A.D.; Cabrera, W.R.; Benítez, J.S.: Morphology and vascularization of ulnar and median nerves in dog brachial region. Rev. vet. 22: 2, 109113,2011 . The objective of this assay was to identify the origin and segmental distribution of blood vessels that constitute the extrinsic vascular system and determine some morphometric parameters of the ulnar and median nerves in the brachial region of the dog. Six canine thoracic limbs were injected with colored latex, then the nerves and their corresponding irrigation were dissected. From nerve trunk cross-sections, histological preparations were prepared and stained with hematoxylin and eosin. The number and distribution of fascicles were determined by light microscopy. Fibers were grouped into two categories according to diameter (up to 6 and more than $6 \mathrm{um}$ ). Measurement of fascicles areas was also carried out and the distance between the epineurium and perineurium was determined. In 57\% of the cases the proximal and distal ulnar and median nerves were supplied by small branches arising from the brachial artery. In the proximal small vessels were also observed to originate from the external thoracic artery and brachial deep. In the distal segment small branches were seen originating from the deep brachial artery and biceps. Considering the conformation and morphology of the proximal segment, it was observed an average of 3 fascicles, an average area of $0.96 \mathrm{~mm} 2$ and a distance of $0.7 \mathrm{~mm}$ between epineurium and perineurium. The diameter of the fibers in this segment determined $40 \%$ corresponding to category 1 and $60 \%$ to category 2 . In the distal segment there was an average of 4 fascicles, an average area of $0.65 \mathrm{~mm} 2$ and a distance of 0.73 $\mathrm{mm}$ between epineurium and perineurium. The diameter of the fibers found in this segment determined $41 \%$ corresponding to category 1 and $59 \%$ to category 2 .
\end{abstract}

Key words: dog, ulnar and medium nerves, fascicles, irrigation. 


\section{INTRODUCCIÓN}

Los nervios cubital y mediano de la región braquial del perro conforman un tronco simple desde la articulación escapulohumeral hasta el tercio medio y distal del brazo, lugar donde se separan y continúan su recorrido hasta la región de los dedos, dando distintas ramificaciones y denominaciones en cada región. Ambos nervios presentan una longitud similar. El tronco combinado de ambos nervios recorre la región del brazo en caudal de la arteria braquial, relacionándose con la cabeza medial del músculo tríceps braquial y el músculo pectoral profundo ${ }^{4,5,8}$.

El aporte sanguíneo de los nervios periféricos lo constituye un plexo vascular complejo, compuesto por dos sistemas arteriales: uno extrínseco y otro intrínseco, anastomosados entre sí. El sistema extrínseco se origina de las arterias vecinas, de los vasos periósticos y musculares adyacentes más pequeños, que se localizan en la superficie del nervio manteniendo una posición relativamente constante a lo largo de toda su longitud, aportando de forma mesoneural un número de arterias nutricias que varían en tamaño y número, penetrando en el nervio a intervalos irregulares. El sistema intrínseco está conformado por los plexos epineural, perineural y endoneural y sus vasos comunicantes 1,2, 6, 10-13,16.

Los sistemas arteriales son tortuosos para permitir el desplazamiento longitudinal amplio del nervio, previa constricción vascular secundaria a la tensión ejercida con los cambios posturales ${ }^{18}$. Para una función adecuada, el nervio periférico requiere una conexión anatómica y fisiológica con los cuerpos neuronales, localizados en el sistema nervioso central y un suministro continuo y conveniente de oxígeno a través del sistema vascular extrínseco e intrínseco ${ }^{14,15,17}$.

Las secciones transversales de los nervios periféricos muestran los axones o fibras nerviosas y su vaina de mielina, circundada por el endoneuro. El perineuro delimita y envuelve cada fascículo y los grupos de fascículos están encerrados por el epineuro, el cual incluye los vasos intraneurales $7,11,19$. Fascículos y epineuro son estructuras importantes al momento de realizar la sutura y la aproximación de los segmentos dañados. Estos conocimientos complementados con el uso de técnicas microquirúrgicas, ayudan a mejorar la especificidad de la reinervación y la recuperación funcional ${ }^{2,6,10,13}$.

Se considera que los troncos nerviosos periféricos presentan distintos tipos de modelos fasciculares en distintos nervios y a distintos niveles dentro del mismo nervio, existiendo en anatomía humana una clasificación en modelos de agrupación fascicular. Las fibras nerviosas, según su función pueden ser motoras o eferentes y sensoriales o aferentes; por su tamaño varían entre 0,2 a 21 um de diámetro, cuanto más grande es éste, mayor es la velocidad de conducción, el intervalo de velocidad de conducción se encuentra entre 0,5 y $120 \mathrm{~m} / \mathrm{seg}^{9}$.

Las fibras nerviosas pueden ser: tipo A mielínicas, típicas de los nervios espinales, de 1 a 21 um, dividiéndose en los subtipos alfa, beta, gama y delta. Las fibras tipo A alfa y beta poseen diámetros que oscilan entre 6 y 21 um, con función motora del músculo esquelético pero también comparten funciones sensitivas en el huso muscular, órgano tendinoso de Golgi, receptores del pelo, vibración (corpúsculo de Pacini) y tacto de alta discriminación (Meissner, terminaciones dilatadas). Las fibras tipo A gama y delta alcanzan diámetros entre 1 y 6 um y corresponden a la función motora del huso muscular y a la función sensitiva de presión, tacto profundo, dolor al pinchazo y sensaciones térmicas. Por su parte las fibras tipo $\mathrm{C}$ son amielínicas muy pequeñas, no superan 0,2 a 1 um de diámetro, conducen impulsos a bajas velocidades y constituyen más del $50 \%$ de las fibras sensitivas de los nervios periféricos y todas las fibras posganglionares autonómicas 9,12 .

En anatomía humana cabe resaltar la ausencia de trabajos específicos sobre morfometría y estereología de los nervios periféricos. De gran interés anatómico, clínico y quirúrgico es conocer aspectos como diámetro de los nervios, perímetro de cada uno de ellos, número de fibras nerviosas, áreas de los fascículos y ramos nerviosos, entre otros parámetros ${ }^{3}$.

El objetivo del trabajo fue identificar el origen y distribución segmentaria de los vasos sanguíneos que constituyen el sistema extrínseco de vascularización y determinar el número, situación espacial de los fascículos, área que ocupan, distancias entre epineuro y perineuro y diámetros de las fibras de los principales fascículos que conforman los nervios cubital y mediano de la región braquial del perro.

\section{MATERIAL Y MÉTODOS}

Se utilizaron seis miembros anteriores de caninos, aplicándose la siguiente metodología: 1) sección del miembro separándolo del tórax; 2) localización y canalización de la arteria axilar; 3) inyección de pasta de repleción vascular (látex neoprene coloreado); 4) reposo de 48 h en cámara fría; 5) extirpación de la piel que cubría el miembro; 6) fijación del material por inmersión en formol al 10\%; 7) disección clásica del tronco nervioso, visualizando el origen de los vasos sanguíneos que constituyen el sistema extrínseco y su distribución segmentaria; 8) documentación fotográfica de las disecciones y esquematización de las observaciones registradas; 9) sección del tronco nervioso en dos segmentos (proximal y distal) en una longitud de $1,5 \mathrm{~cm}$ colocando hilos de color rojo y azul que incluían el epineuro longitudinalmente en una extensión de 0,5 $\mathrm{cm}$., el hilo de color rojo indicó la posición lateral, el hilo de color azul la posición craneal; 10) fijación de los segmentos con formol buffer al $10 \%$ durante $24 \mathrm{~h}$; 11) inclusión en parafina; 12) realización de cortes con micrótomo tipo Minot a $5 \mathrm{um}$; 13) tinción con hematoxilina y eosina; 14) observación en microscopio óptico identificando el número y distribución fascicular; 15) medición del área de los fascículos; 16) determinación de los diámetros de 100 fibras en los principales fascículos y agrupación de las mismas en dos categorías 
(categoría 1: hasta 6 um: categoría 2, más de 6 um); 16) medición de la distancia entre epineuro y perineuro a partir de fotografías obtenidas, empleando el analizador de imágenes Image Pro-Plus, versión 4.5, Media Cybernetics Inc.

\section{RESULTADOS Y DISCUSIÓN}

En el 57\% de los casos, los segmentos proximal y distal de los nervios cubital y mediano, estaban irrigados por pequeñas ramas que se desprendían de la arte-

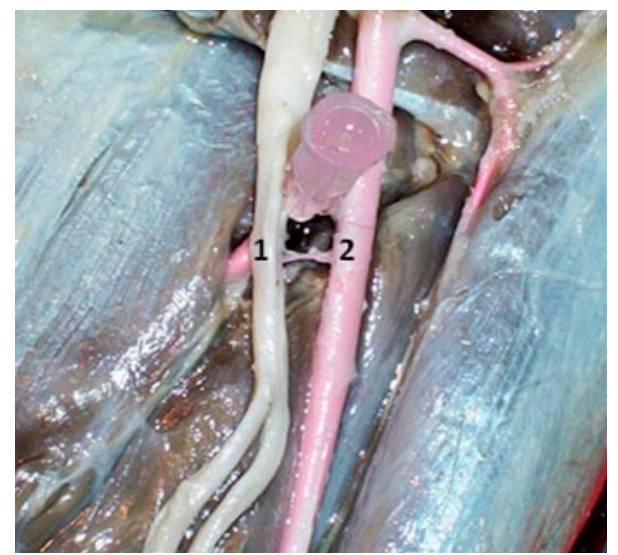

Figura 1. 1: tronco proximal de los nervios cubital y mediano; 2: arteria braquial.

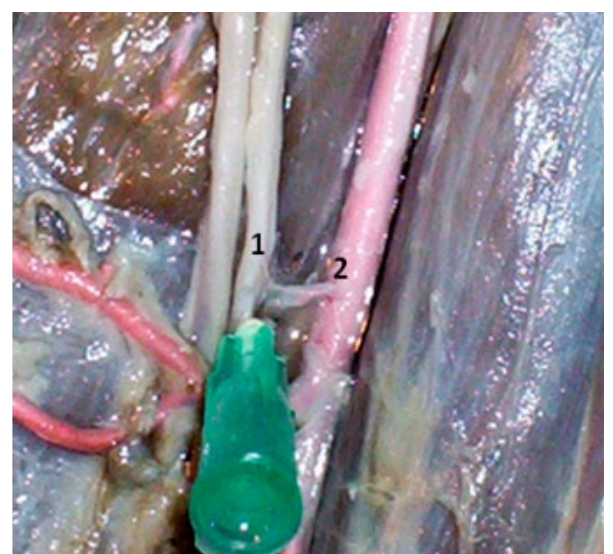

Figura 2. 1: Segmentos distales de los nervios cubital y mediano; 2: Arteria braquial.

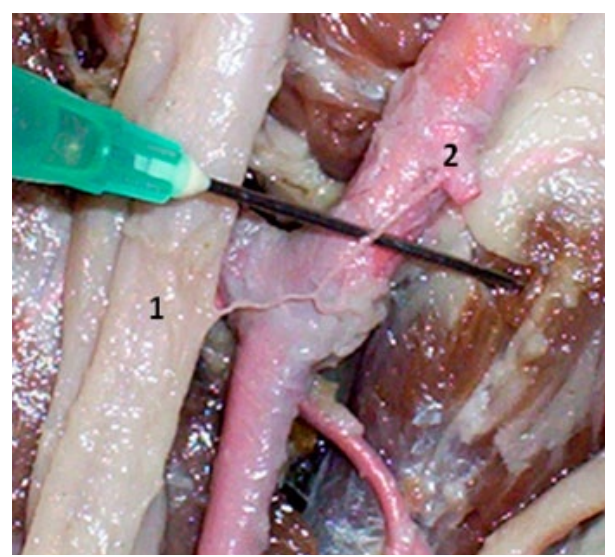

Figura 3. 1: Segmentos proximales de los nervios cubital y mediano; 2 : Arteria torácica externa. ria braquial (Figuras 1 y 2). En el segmento proximal también se observaron pequeños vasos que se originaban de la arteria torácica externa (Figura 3) y braquial profunda (Figura 4). En el segmento distal se observaron además, pequeñas ramas originadas de la arteria bicipital (Figura 5) y braquial profunda (Figura 6). En cuanto a la morfometría, en el segmento proximal se observó un promedio de 3 fascículos (Figura 7), un área promedio de $0,96 \mathrm{~mm}^{2}$ y una distancia epineuroperineuro de $0,7 \mathrm{~mm}$. La medición del diámetro de las fibras en este segmento (Figura 8) determinó un 40\%

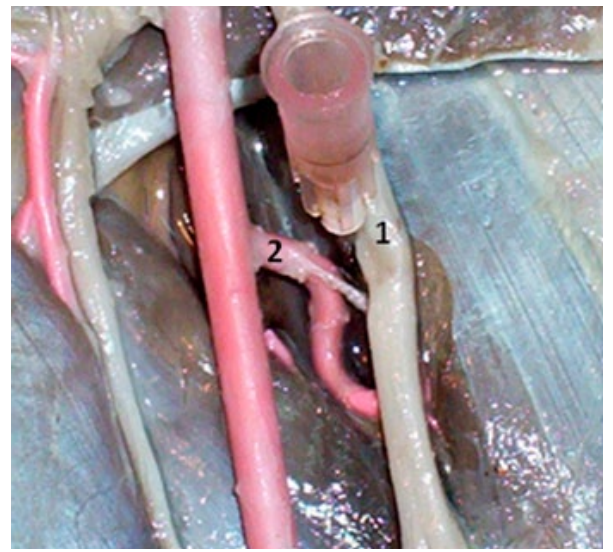

Figura 4. 1: Segmentos proximales de los nervios cubital y mediano; 2: Arteria braquial profunda.

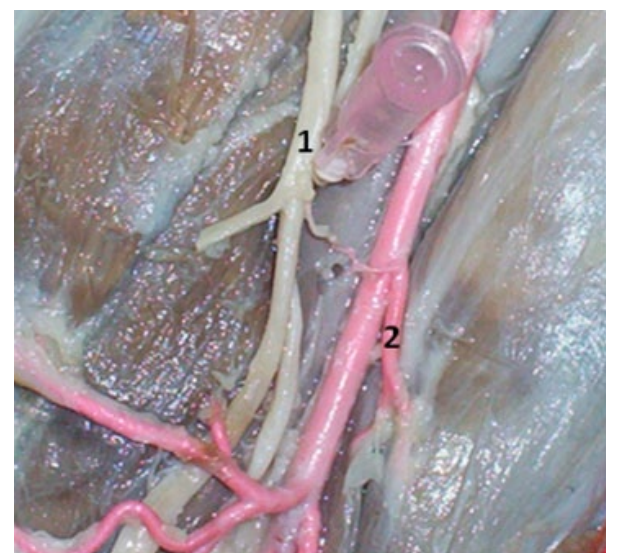

Figura 5. 1: Segmentos distales de los nervios cubital y mediano; 2: Arteria bicipital.

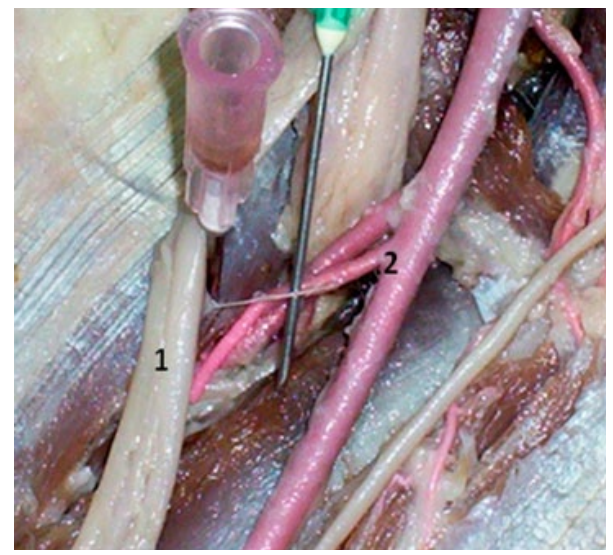

Figura 6. 1: Segmentos distales de los nervios cubital y mediano; 2: Arteria braquial profunda. 


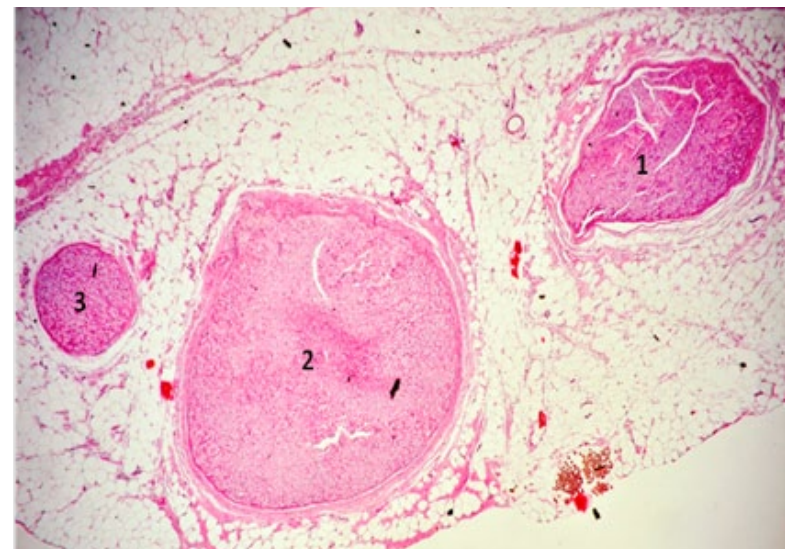

Figura 7. Fascículos del segmento proximal. 1: fascículo craneal; 2: fascículo intermedio; 3: fascículo caudal. HyE, $4 x$.

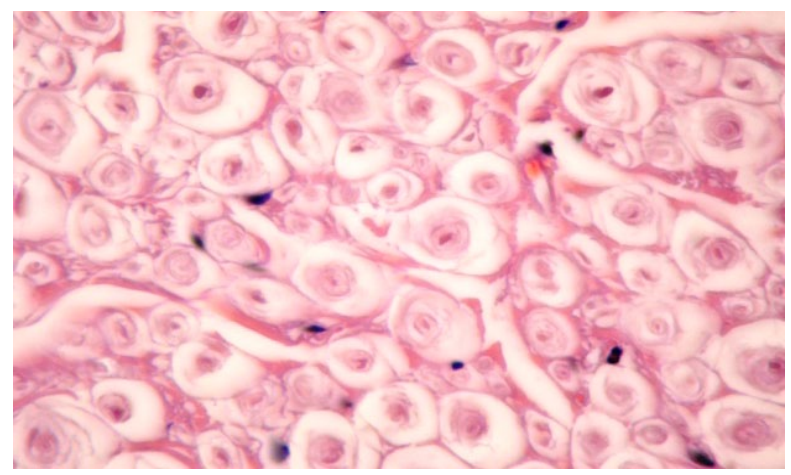

Figura 8. Fibras nerviosas del segmento proximal. HyE, 100x.

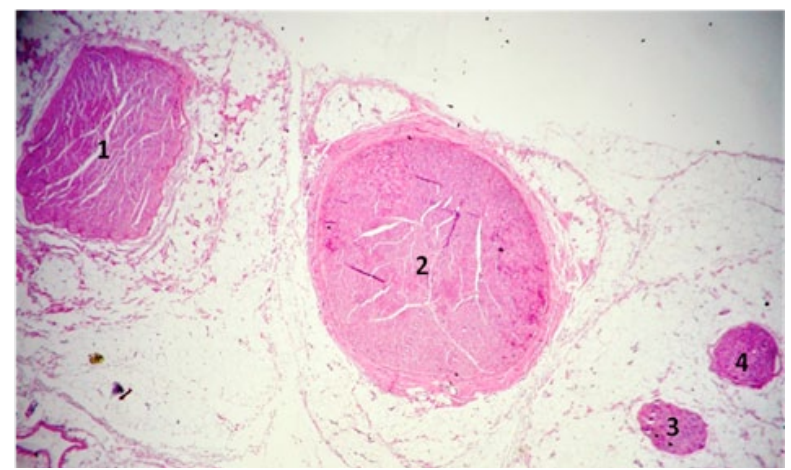

Figura 9. Fascículos del segmento distal. 1: fascículo craneal; 2: fascículo intermedio; 3: fascículo caudal lateral; 4: fascículo caudal medial. HyE, 4x.

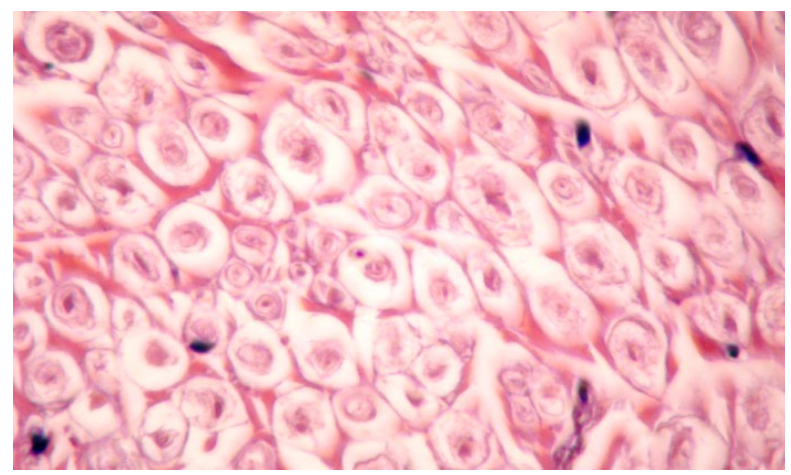

Figura 10. Fibras nerviosas del segmento distal. HyE, $100 x$. de inclusión en la categoría 1 y un $60 \%$ en la categoría 2. En el segmento distal se observó un promedio de 4 fascículos (Figura 9), un área promedio de $0,65 \mathrm{~mm}^{2} \mathrm{y}$ una distancia epineuro-perineuro de $0,73 \mathrm{~mm}$. La medición del diámetro de las fibras en este segmento (Figura 10 ), determinó un $41 \%$ de inclusión en la categoría 1 y $59 \%$ de inclusión en la categoría 2.

Las descripciones efectuadas sobre la vascularización y morfometría del nervio cubital y mediano de la región braquial del perro, aportan al mejor conocimiento de la anatomía, brindando una contribución útil a la cirugía traumatológica, especialmente en las reparaciones nerviosas ${ }^{1,6,11,14,15}$.

\section{REFERENCIAS}

1. Ayala Gutiérrez H, Colas San Juan C, Palacios JI, Morrondo JC. 2001. Cirugía secundaria de las lesiones de los nervios periféricos. www.secpre.org/documentos.

2. Chrisman CH. 1996. Neuropatías periféricas. En: Fisiopatología y clínica quirúrgica en animales pequeños (Bojrab MJ, Ed.), InterMédica, Buenos Aires, p. 1192-1206.

3. Del Sol M, Olave E, Contreras J, Vásquez B. 2010. Morfometría de los nervios isquiático, tibial y fibular común en el hombre. Int J Morphol 28: 385-388.

4. Dyce KM, Sack WO, Wensing CJ. 1999. Anatomía veterinaria, Panamericana, México, p. 30-32 y 338-350.

5. Evans H, Delahunta A. 2000. Disección del perro, McGraw-Hill, México, p. 160-181 y 241-265.

6. Garibaldi L. 2003. Monoparesias y monoplejias. En: El libro de neurología para la práctica clínica (Pellegrino $\mathrm{F}$, Suraniti A, Garibaldi L, Ed), InterMédica, Buenos Aires, p. 161-167.

7. Geneser F. 1990. Histología, Panamericana, Madrid, p. 296-298.

8. Getty R. 1982. Anatomía de los animales domésticos, Salvat, Barcelona, p. 209-221 y 1862-1887.

9. Guyton AC. 1997. Anatomía y fisiología del sistema nervioso, Panamericana, Madrid, p. 123-125.

10. Luhers D, Riet G, Pioli M. 2003. Citología del sistema nervioso periférico y su relevancia en las enfermedades neurológicas. En: El libro de neurología para la práctica clínica (Pellegrino F, Suraniti A, Garibaldi L, Ed), InterMédica, Buenos Aires, p. 622-626.

11. Marin M, Castello JR, Santos J. 2001. Lesiones agudas de los nervios periféricos. www.secpre.org/documentos.

12. Pellegrino F, Sánchez G. 1995. Anatomía funcional del sistema nervioso de los animales domésticos, Ed. AgroVet, Buenos Aires, p.13-37.

13. Pérez R, Labrador JM, Lara F, Marcos A, Hijano JC, Martínez R, Cabrera E. 2001. Injertos (cutáneos, dermograsos, tendinosos, nerviosos, óseos, cartilaginosos y vasculares). www.secpre.org/documentos.

14. Rodkey WG. 1993. Peripheral nerve surgery. En: Textbook of small animal surgery (Slatter D, Ed.), Saunders, Philadelphia, p. 1135-1141.

15. Seddon HJ. 1972. Surgical disorders of the peripheral nerves, Williams \& Wilkins, Baltimore, $332 \mathrm{p}$. 
16. Shores A. 2001. Sistema nervioso y órganos de la sensación. En: Técnicas actuales en cirugía de pequeños animales (Bojrab MJ, Ed.). InterMédica, Buenos Aires, p. 67-76.

17. Steinberg HS. 1988. Brachial plexus injuries and dysfunctions. Vet Clin North Am: Small Anim Pract 18: 565580 .
18. Sunderland S. 1985. Nervios periféricos y sus lesiones, Salvat, Barcelona, $780 \mathrm{p}$.

19. Ueyama T. 1978. The topography of root fibres within the sciatic nerve trunk of the dog. J. Anat 127: 277-290.

\section{Revista Veterinaria ya registra "índice de impacto"}
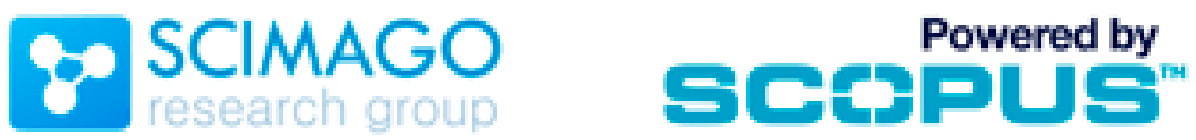

Así lo informó The SCImago Journal \& Country Ranks, un portal que difunde indicadores científicos de revistas internacionales, desarrollados a partir de la información contenida en la base de datos de Scopus (Elsevier), indicadores aptos para evaluar y analizar distintos dominios científicos.

Para el período 1996-2008, el ranking latinoamericano de documentos citables incluyó países como Brasil (6804), Argentina (1186), México (1199), Venezuela (713), Chile (658), Uruguay (201) y Colombia (166). El resto de los países registró menos de 100 documentos citables en dicho período.

En Argentina, para el rubro "Veterinaria" (1996-2008) se registraron 1096 documentos, de los cuales 1079 fueron citables, efectuándose 7617 citaciones. "Revista Veterinaria” (UNNE, Corrientes) registró un índice de impacto de 0,03 .

El indicador SJR mide la influencia científica promedio de los artículos de una publicación periódica, reflejando su participación en la discusión científica global de la disciplina considerada. El índice se calcula por medio de la fórmula Thomson Reuters, que se aplica para evaluar el factor de impacto de la revista.

Fuente: http://www.scimagojr.com. Retrieved September 20, 2010. 